\title{
Microwave assisted fluidized bed drying of celery
}

\section{Kaur, A. *; Gariépy, Y.; Orsat, V.; Raghavan, V.}

Department of Bioresource Engineering, McGill University, St-Anne-de-Bellevue, Quebec, Canada.

*Email of the corresponding author: amanat.kaur@mail.mcgill.ca

\begin{abstract}
The drying kinetics of celery in a microwave assisted fluidized bed dryer was studied at different drying air temperatures $\left(45^{\circ} \mathrm{C}, 55^{\circ} \mathrm{C}\right.$ and $\left.65^{\circ} \mathrm{C}\right)$ and at different initial microwave power densities $(0 \mathrm{~W} / \mathrm{g}, 1 \mathrm{~W} / \mathrm{g}$ and $2 \mathrm{~W} / \mathrm{g})$. Dried product quality, product mass, air temperature, air relative humidity, and electric power consumption were used to monitor the performance of the drying process. The results showed that the Midilli-Kucuk model was best in predicting the moisture ratio as a function of drying time. At any given temperature, the utilization of the microwave energy reduced by more than $50 \%$ the drying time.
\end{abstract}

Keywords: drying; celery; $M W F B D$. 


\section{Introduction}

The ethical implications involved with increasing world food insecurity and food wastage has led researchers to look for methods to reduce food wastage. Drying is one of the oldest and best methods that can be successfully used to reduce food loss and increase shelf-life. Drying results in reduction of spoilage of perishable food, and requirements for product storage and transportation. Various drying methods can be used to achieve the desired dried products; the choice of the dryer depends upon product requirements and process parameters.

Drying using hot air is efficient for falling rate period but takes longer time for constant drying rate period due to high resistance to moisture transfer and reduction in thermal conductivity of the product. Application of microwaves, in addition to hot air, helps in reducing drying times and results in better efficiencies for the constant drying rate period. This increase in efficiency can be attributed to the volumetric heating of the product exposed to microwave energy which leads to evaporation of internal moisture, which creates a pressure gradient for liquid and vapor transfer [1]. In addition, use of hot air with fluidization moves the evaporated moisture away from the surroundings of the product [1].

Celery is a high moisture commodity and it is extremely perishable. Celery is a popular ingredient used in soups and stews to enhance the flavor and aroma [2, 3]. Celery has significant amount of essential oils with different terpenes and limonenes [4], and it is a good source of various vitamins and minerals [2, 4]. It has been used as aphrodisiacs, anthelmintics, antispasmodics, sedatives, stimulants, and tonics. Some authors have reported its beneficial effects to treat against asthma, bronchitis and rheumatism [2-4]. Celery can be used by diabetics or people on low sodium diets due to the presence of an active component similar to insulin [3].

Several studies can be found on drying celery and celery leaves such as microwave drying of celery leaves $[5,6]$, effect of microwave power on celery leaves in microwave drying [2], and vacuum drying of celery [3]. Zaremba (2007) developed a model and concluded that drying time for sliced celery in fluidized bed was less than fixed bed for same drying temperature [7]. Karathanos (1993) reported on the effects of freeze drying and air drying on the internal structure and final product quality [8].

Drying kinetics is used for the design of drying processes [9]. Drying kinetics behavior helps in the design, optimization and simulation of the drying process [10]. Also, mathematical modeling and simulations are commonly used to optimize the drying process and to improve the final product quality [9]. Optimizing process parameters such as air temperature, microwave power density and air flow rate [11] ensure that the quality attributes such as color, shape, nutritional composition and texture are preserved [12].

The aim of this study was to investigate the drying kinetics of celery in microwave fluidized bed dryer and to assess the effects of drying conditions on the quality of final dried product. 


\section{Materials and Methods}

\subsection{Experimental Procedure}

A central composite design was used to study the effects of initial microwave power density (IMPD) and air temperature on the quality of celery in a microwave assisted fluidized bed dryer. The IMPD (W/g) was the applied microwave power at the start of the drying process divided by the initial mass of the product. Both factors had 3 levels each; with initial microwave power density of $0 \mathrm{~W} / \mathrm{g}, 1 \mathrm{~W} / \mathrm{g}$ and $2 \mathrm{~W} / \mathrm{g}$, and drying air temperature of $45^{\circ} \mathrm{C}, 55^{\circ} \mathrm{C}$ and $65^{\circ} \mathrm{C}$. No pretreatments were done in this study. Data acquired was used to determine optimum drying conditions based upon product quality parameters and drying time. Parameters recorded and compared were the drying time, change in color, rehydration ratio, and texture of the rehydrated product. The product mass, air velocity, air and bed temperature were recorded at 10 mins intervals. At start, the dryer was run empty to reach steady state conditions. The sliced celery was then added to the drying chambers and the drying cycle was started. A data acquisition system (DAQ) Agilent 34970A was used to record and store process conditions measured by different sensors connected to the dryer. Drying time of the product was the time required to reach final moisture content of $15 \%$ wet basis (wb). All trials were performed with $250 \mathrm{~g}$ of freshly sliced celery pieces. As the drying progressed, the air velocity was adjusted to maintain good fluidization.

\subsection{Celery}

Fresh celery was bought from local markets and stored in plastic bags in a refrigerator at $4^{\circ} \mathrm{C}$. Initial moisture content of celery was determined before each run. It averaged at $94.5 \pm$ $0.5 \% \mathrm{wb}$. Prior to drying, the celery was sliced into pieces using an onion chopper (Starfrit model 093413, Atlantic Promotions Inc., Canada). The chopper blades assembly had opening of $12 \mathrm{~mm}$ by $12 \mathrm{~mm}$.

\subsection{Microwave Fluidized Bed Dryer}

The schematic diagram of the microwave fluidized bed drying system is presented in Figure 1. An experimental microwave oven (Panasonic Inc., CA) with a maximum output of $700 \mathrm{~W}$ at $2450 \mathrm{MHz}$ was modified for the drying experiments. Two $2 \mathrm{~kW}$ hot-air heaters were used to preheat the air and they were controlled by the same PID controller (CN9500, Temperature Controller, Omega, USA). The fluidization chamber was made of glass with dimensions of $100 \mathrm{~mm}$ in diameter by $300 \mathrm{~mm}$ in length and it was installed inside the microwave cavity. Perforated plates made of polypropylene were placed at the bottom and top of the fluidizing chamber, and attached to the wall of the microwave cavity. Humidity sensors, temperature probes, and anemometers were installed at different locations inside the air distribution system (Figure 1). Power sensors were used to monitor electrical consumption of heaters, blower and microwave. 


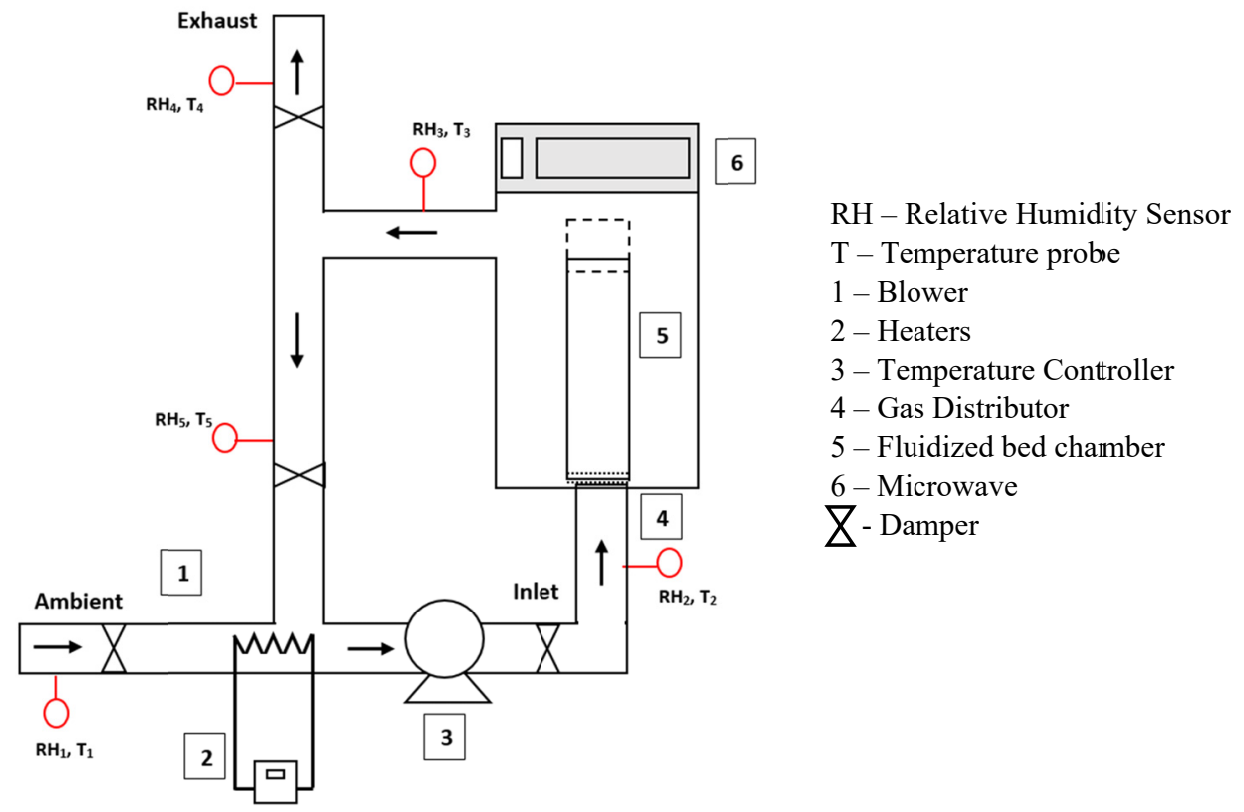

Figure 1. Schematic diagram of the fluidized bed dryer

\subsection{Drying Kinetics}

Predictive mathematical models found in the literature [13] were used to study the drying kinetics of sliced celery in the microwave assisted fluidized bed dryer. These models express the relationship between the moisture ratio (MR) and the drying time.

$\mathrm{MR}$ is dimensionless and it was calculated using the following equation:

$$
\mathrm{MR}=\frac{\mathrm{M}_{\mathrm{t}}-\mathrm{M}_{\mathrm{e}}}{\mathrm{M}_{\mathrm{o}}-\mathrm{M}_{\mathrm{e}}}
$$

where $M R$ is the moisture ratio (dimensionless), $M_{o}$ is the moisture content dry basis (db) at time $\mathrm{t}=0, \mathrm{M}_{\mathrm{t}}$ is the moisture content $(\mathrm{db})$ at time $\mathrm{t}$, and $\mathrm{M}_{\mathrm{e}}$ is the equilibrium moisture content $(\mathrm{db})(=17.647 \%)$.

Drying time to reach $15 \%$ moisture content (wb) was also calculated and compared to assess the effects of drying conditions.

\subsection{Dried Product Properties}

The final moisture content of the product was determined by oven drying at $70^{\circ} \mathrm{C}$ until constant mass was achieved.

Rehydration capacity is an important factor in products that can be used for instant soups [14]. The rehydration capacity of the dried product was determined by immersing $1 \mathrm{~g}$ of the dried celery in boiling water for 20 mins. It was done in triplicates for all drying conditions. 


$$
\mathrm{RR}=\frac{\mathrm{M}_{\mathrm{r}}}{\mathrm{M}_{\mathrm{d}}}
$$

where RR is the Rehydration Ratio (dimensionless), $M_{r}$ is the mass of the rehydrated product $(\mathrm{g})$, and $\mathrm{M}_{\mathrm{d}}$ is the mass of the dried product $(\mathrm{g})$.

Visual and textural attributes are important sensory parameters of a food product. Reactions such as pigment degradation (such as carotenoids and chlorophyll), and browning reactions takes place during thermal processing of food products leading to color changes and need to be monitored [5]. A Minolta Chromameter Model CR-300 (Minolta Co. Ltd., Japan) was used to measure the color of the rehydrated samples using the CIE Lab color space. These values were then used to measure the change in color $(\Delta \mathrm{E})$ between the fresh and the rehydrated sample. The mechanical properties of the rehydrated samples were measured with an Instron Universal Testing Machine (Instron-4502, Instron Corporation, USA) equipped with a Kramer shear press. The Kramer shear cell was used because it simulates the effect of a single bite. The parameters recorded included the energy required to compress and shear the sample, and the maximum force applied. Texture measurements were made in triplicates.

\section{Results and Discussion}

\subsection{Drying Kinetics}

A typical curve representing the changes of moisture content against the drying time is shown in Figure 2.

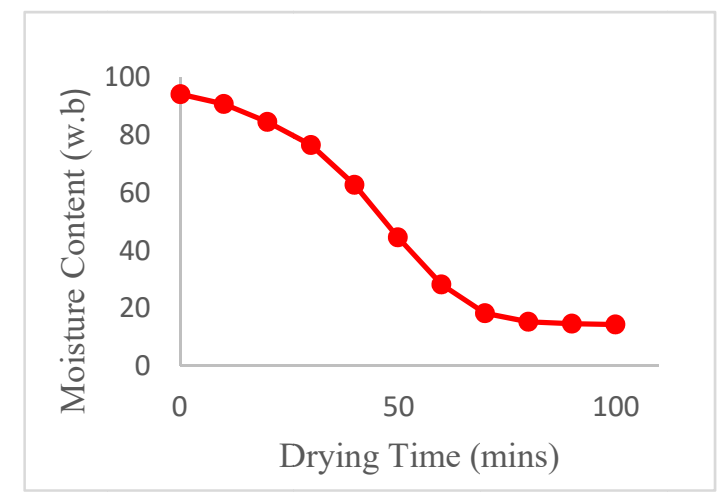

Figure 2. Moisture content vs drying time for drying air temperature $55^{\circ} \mathrm{C}$ and initial microwave power density (IMPD) $1 \mathrm{~W} / \mathrm{g}$

Figures 3 and 4 represent typical MR curves for microwave assisted fluidized bed drying of celery at different temperatures and microwave power density. Slope of the drying curves indicate the speed of mass transfer within the sample for the operating conditions used in the drying process. As seen in Figures, the slope of the drying curves increased with increase in temperature and microwave power density. 


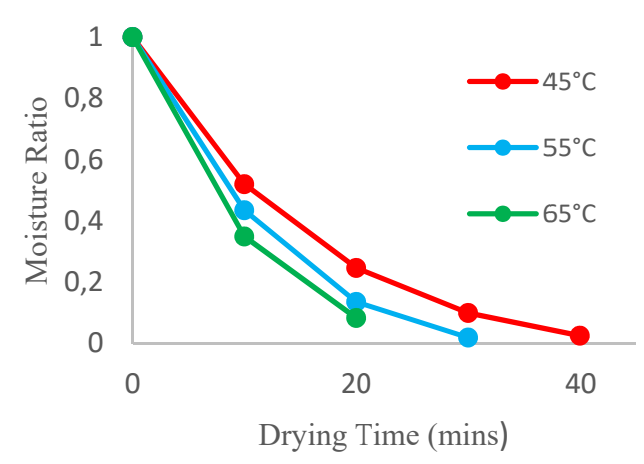

Figure 3. Effect of air temperature at initial microwave power density (IMPD) of $2 \mathrm{~W} / \mathrm{g}$ on moisture ratio during the drying process

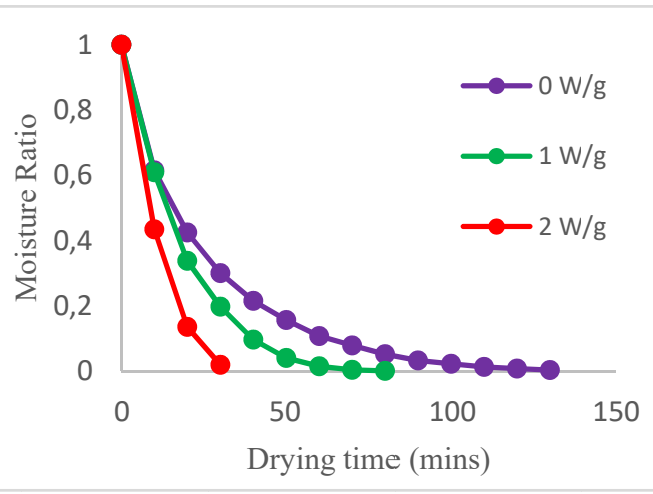

Figure 4. Effect of initial microwave power density at drying air temperature $55^{\circ} \mathrm{C}$ on moisture ratio during the drying process

\subsubsection{Mathematical Model}

Out of all the models studied, the Midilli-Kucuk equation was the best model to predict the MR as a function of drying time for drying celery in a microwave assisted fluidized bed dryer at $55^{\circ} \mathrm{C}$ and $1 \mathrm{~W} / \mathrm{g}$ (Figure 5). The general form of the Midilli-Kucuk equation can be written as:

$$
\mathrm{MR}=a e^{-k(t)^{n}}+b t,
$$

where $\mathrm{a}$ is a coefficient (dimensionless), $\mathrm{b}$ is a coefficient $\left(\mathrm{min}^{-1}\right), \mathrm{t}$ is the dying time (min), $\mathrm{k}$ is the drying rate constant $\left(\mathrm{min}^{-1}\right)$, and $\mathrm{n}$ is a dimensionless parameter.

The model had highest $\mathrm{R}^{2}$ and lowest SSE values amongst 9 drying models used in this study (Table 1) and similar results were reported by Demirhan and Ozbek (2011) for microwave drying of celery leaves [2].

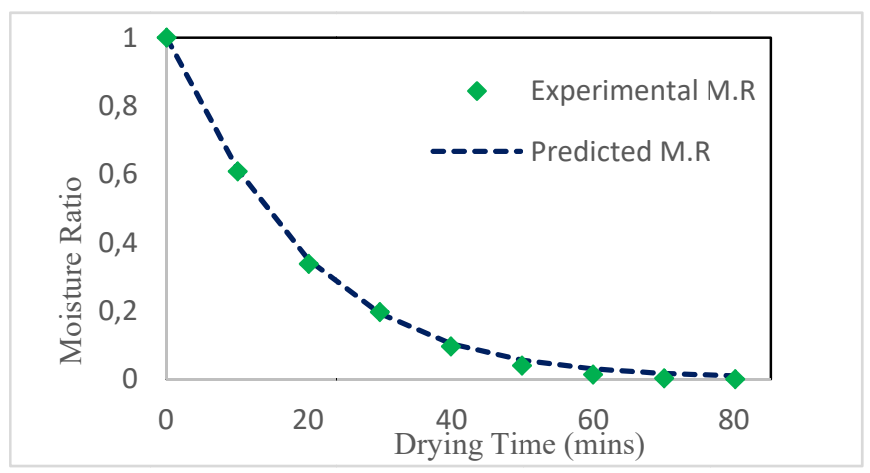

Figure 5 Moisture ratio against drying time for experimental and mathematical model at $T=55^{\circ} \mathrm{C}$ and IMPD $=1 \mathrm{~W} / \mathrm{g}$ (Midilli-

\section{Kucuk Equation).}


Kaur, A.; Gariépy, Y.; Orsat, V.; Raghavan, $V$.

Table 1 Statistical values for different drying conditions

\begin{tabular}{llllllll}
\hline Temp & IMPD & SSE & $\mathbf{R}^{2}$ & $\mathbf{a}$ & $\mathbf{k}$ & $\mathbf{n}$ & $\mathbf{b}$ \\
\hline 45 & 0 & $2.16 \mathrm{E}-04$ & 0.9998542 & 0.999 & 0.03863 & 0.9247 & $-9.29 \mathrm{E}-08$ \\
55 & 0 & $2.10 \mathrm{E}-04$ & 0.9998294 & 0.9977 & 0.06697 & 0.844 & $4.48 \mathrm{E}-06$ \\
65 & 0 & $3.70 \mathrm{E}-05$ & 0.9999654 & 1 & 0.06779 & 0.9083 & $3.71 \mathrm{E}-05$ \\
45 & 1 & $5.65 \mathrm{E}-04$ & 0.9994403 & 0.9984 & 0.07668 & 0.854 & $-1.99 \mathrm{E}-04$ \\
65 & 1 & $9.63 \mathrm{E}-05$ & 0.999881 & 0.9998 & 0.05613 & 1.098 & $-6.36 \mathrm{E}-05$ \\
55 & 1 & $3.03 \mathrm{E}-04$ & 0.9997072 & 0.9995 & 0.03814 & 1.108 & $3.12 \mathrm{E}-05$ \\
55 & 1 & $4.45 \mathrm{E}-04$ & 0.9995424 & 0.9992 & 0.06708 & 0.97 & $6.97 \mathrm{E}-06$ \\
55 & 1 & $2.68 \mathrm{E}-04$ & 0.9997061 & 0.9994 & 0.05343 & 1.044 & $-4.67 \mathrm{E}-05$ \\
55 & 1 & $1.29 \mathrm{E}-04$ & 0.9998578 & 0.9984 & 0.05322 & 1.045 & $-4.62 \mathrm{E}-05$ \\
55 & 1 & $1.62 \mathrm{E}-04$ & 0.9998162 & 0.9993 & 0.07159 & 0.9457 & $-1.03 \mathrm{E}-04$ \\
45 & 2 & $1.77 \mathrm{E}-04$ & 0.9997845 & 0.9995 & 0.04842 & 1.118 & $-2.46 \mathrm{E}-04$ \\
55 & 2 & $1.14 \mathrm{E}-04$ & 0.9998524 & 0.9993 & 0.0433 & 1.276 & $2.46 \mathrm{E}-05$ \\
65 & 2 & $3.62 \mathrm{E}-15$ & 1 & 0.9999 & 0.07282 & 1.143 & $-7.38 \mathrm{E}-04$ \\
\hline
\end{tabular}

\subsubsection{Drying Time}

The drying time to reach $15 \%$ moisture content was calculated for all drying conditions studied and a predictive model was derived (Figure 6). This model can be used to predict drying time as a function of air temperature and IMPD and it is presented below:

$$
t=222.9276-1.683 \times \mathrm{T}-50.725 \times \mathrm{IMPD},\left(\mathrm{R}^{2}=0.9187\right)
$$

where $\mathrm{t}$ is the drying time (mins), $\mathrm{T}$ is the Temperature $\left({ }^{\circ} \mathrm{C}\right)$; and IMPD is the initial microwave power density (IMPD) (W/g).

Over the range studied, it was observed that IMPD had more effect on drying time than air temperature. At any given temperature, the drying was reduced by more than $50 \%$ when microwave energy was added to the drying process. These results are in agreement with those reported by Alibas [6] on microwave drying of celery leaves. Similar results have been reported by Reyes et al. [15] on microwave drying of potato slices and by Maskan [16] on Kiwifruits. In addition to the positive effect of microwave energy on drying time, fluidization ensured that the product is uniformly dried and it minimized the formation of agglomerates. [17] 




Figure 6. Response surface of the predicted drying time as a function of IMPD $(\mathrm{W} / \mathrm{g})$ and air temperature $\left({ }^{\circ} \mathrm{C}\right)$

\subsection{Product Quality Characteristics}

\subsubsection{Color}

Color measurements made on the rehydrated samples indicated that the lowest values of $\Delta \mathrm{E}$ were obtained at $55^{\circ} \mathrm{C}$. The analysis of variance performed on the collected data indicated that the drying air temperature had no significant effect on $\Delta \mathrm{E}$ and only microwave power had induced changes in color. Changes in color $\Delta \mathrm{E}$ was therefore modeled as a function of IMPD and yielded the following equation:

$$
\Delta \mathrm{E}=11.712-1.5325 \times \mathrm{IMPD}-0.6705 \times \mathrm{IMPD}^{2},\left(\mathrm{R}^{2}=0.411125\right)
$$

where IMPD is the initial microwave power density $(\mathrm{W} / \mathrm{g})$.

This equation indicates that $\Delta \mathrm{E}$ was inversely related to IMPD, i.e., color change decreases with increase in microwave power density.

\subsubsection{Rehydration Ratio}

The analysis performed on the rehydration ratio indicated that only air temperature had a significant effect. It was observed that rehydration ratio decreased with increasing air temperature. The predictive model for the rehydration ratio as a function of drying air temperature is as follows:

$$
\mathrm{RR}=27.90-0.781 \times \mathrm{T}+0.00649 \times \mathrm{T}^{2},\left(\mathrm{R}^{2}=0.6283\right)
$$

where $\mathrm{T}$ is the drying air temperature $\left({ }^{\circ} \mathrm{C}\right)$.

\subsubsection{Texture}

The effect of process conditions on the mechanical properties of the rehydrated celery pieces was measured and compared. The collected data indicated that mechanical properties 
were affected by the drying conditions. Both energy to break and maximum force recorded increased with increasing drying air temperature. Although the IMPD did not have significant effect on the energy to break, it did affect the maximum force recorded. The predictive model describing the effects of temperature and IMPD on the maximum force is as follow:

$$
\mathrm{F}=-151.120+8.330 \times \mathrm{T}-38.016 \times \mathrm{IMPD},\left(\mathrm{R}^{2}=0.5649\right)
$$

where $\mathrm{F}$ is the maximum force applied to crush the sample $(\mathrm{N}), \mathrm{T}$ is the drying air temperature $\left({ }^{\circ} \mathrm{C}\right)$, and IMPD is the initial microwave power density $(\mathrm{W} / \mathrm{g})$.

\section{Conclusion}

In the current study, drying kinetics of celery in microwave fluidized bedl drying was investigated. The results showed that the drying time reduced with the addition of microwaves and higher temperatures. Among the different predictive models studied, the Midilli-Kucuk model was found to be the best model for celery in microwave assisted fluidized drying. Rehydration ratios of celery were found to decrease with increasing air temperature and they were not affected by the application of microwave. Amounts of energy to crush the rehydrated samples increased with increasing air temperature but it was not affected by microwave energy. On the other hand, the maximum force required to crush the sample were found to be affected by both temperature and microwave power density.

\section{Acknowledgements}

The authors are grateful to the Natural Sciences and Engineering Research Council of Canada (NSERC) and ministère de l'Agriculture, des Pêcheries et de l'Alimentation du Québec (MAPAQ) for the financial support.

\section{Bibliography}

[1] Feng, H., J. Tang, and R. Cavalieri, Combined microwave and spouted bed drying of diced apples: effect of drying conditions on drying kinetics and product temperature. Drying technology, 1999. 17(10): p. 1981-1998.

[2] Demirhan, E. and B. Özbek, Thin-layer drying characteristics and modeling of celery leaves undergoing microwave treatment. Chemical Engineering Communications, 2011. 198(7): p. 957975.

[3] Madamba, P.S. and F.A. Liboon, Optimization of the vacuum dehydration of celery (Apium graveolens) using the response surface methodology. Drying Technology, 2001. 19(3-4): p. 611626.

[4] Ježek, D., et al., Dehydration of celery by infrared drying. Croatica Chemica Acta, 2008. 81(2): p. 325-331.

[5] Demırhan, E. and B. Özbek, Color change kinetics of celery leaves undergoing microwave heating. Chemical Engineering Communications, 2011. 198(10): p. 1189-1205.

[6] Alibas, I., Mathematical modeling of microwave dried celery leaves and determination of the effective moisture diffusivities and activation energy. Food Science and Technology (Campinas), 2014. 34(2): p. 394-401.

[7] Zaremba, R. and M. Jaros, Theoretical model for fluid bed drying of cut celery. Polish Journal of Food and Nutrition Sciences, 2007. 57(2 [A]): p. 211-214.

[8] Karathanos, V., Collapse of structure during drying of celery. Drying Technology, 11993. 11(5): p. 1005-1023. 
[9] Khoshtaghaza, M.H., H. Darvishi, and S. Minaei, Effects of microwave-fluidized bed drying on quality, energy consumption and drying kinetics of soybean kernels. Journal of food science and technology, 2015. 52(8): p. 4749-4760.

[10] Senadeera, W., et al., Influence of shapes of selected vegetable materials on drying kinetics during fluidized bed drying. Journal of Food Engineering, 2003. 58(3): p. 277-283.

[11] Marella, C. and K. Muthukumarappan, Processing Aids for Improving Heat Transfer during Drying of Granular Food Materials. Journal of Food Processing \& Technology, 2013. 2013.

[12] Kompany, E., et al., DEHYDRATION KINETICS AND MODELLING. Drying Technology, 1993. 11(3): p. 451-470.

[13] Zang, F., Evaluation of Drying Behavior of Broccoli (Brassica oleracea L.) in Hot air and Microwave Drying Systems. 2015, McGill University.

[14] Sanjuán, N., et al., Modelling of broccoli stems rehydration process. Journal of Food Engineering, 1999. 42(1): p. 27-31.

[15] Reyes, A., et al., A comparative study of microwave-assisted air drying of potato slices. Biosystems Engineering, 2007. 98(3): p. 310-318.

[16] Maskan, M., Drying, shrinkage and rehydration characteristics of kiwifruits during hot air and microwave drying. Journal of Food Engineering, 2001. 48(2): p. 177-182.

[17] Goksu, E.I., G. Sumnu, and A. Esin, Effect of microwave on fluidized bed drying of macaroni beads. Journal of Food Engineering, 2005. 66(4): p. 463-468. 